\title{
System Safety Assessment Based on Past Incidents in Oil and Gas Industries: A Focused Approach in Forecasting of Minor, Severe, Critical, and Catastrophic Incidents, 2010-2015
}

\author{
Praveen Patel $^{1}$ and Nagendra Sohani ${ }^{2}$ \\ ${ }^{1}$ Department of Mechanical Engineering, Suresh Gyan Vihar University, Jaipur, Rajasthan, India \\ ${ }^{2}$ Department of Mechanical Engineering, University of Devi Ahilya Vishwavidyalaya, Indore, Madhya Pradesh, India \\ Correspondence should be addressed to Praveen Patel; praveenpatelips@gmail.com
}

Received 30 May 2016; Revised 21 November 2016; Accepted 22 November 2016

Academic Editor: Wei Zhou

Copyright ( $) 2016$ P. Patel and N. Sohani. This is an open access article distributed under the Creative Commons Attribution License, which permits unrestricted use, distribution, and reproduction in any medium, provided the original work is properly cited.

\begin{abstract}
Accident in an occupation which occurred due to series of repetitive minor incidents within the working environment. This work demonstrates the critical system safety assessment based on various incidents that took place to the different system and subsystem of two Indian oil refineries in five years of span 2010 to 2015. The categorization of incidents and hazard rate function of each incident category were classified and calculated. The result of Weibull analysis estimators in the form of scale and shape parameters provides useful information of incidents forecasting and their patterns in a particular time.
\end{abstract}

\section{Introduction}

The safety assurance in the oil refineries is the biggest challenge in front of National Technocrats and Professional due to mass hazardous material handling, transportation, and storage. The hazardous material characteristics in the form of flammability, toxicity, and reactivity strengthen the presence of hazard in every portion of oil refinery.

There has been growing awareness of the problems associated with industrial growth and technological development in last two decades. The existence of the problem in the form of hazard is due to combination of many factors. Technological development in oil refinery is even rapid and of large scale. Presence of hazard in an oil refinery facility is the root cause of accident occurrence. Accident takes place when hazard is transformed into harmful event. Therefore identification and elimination of hazards is essential from the work system. Hazard identification in different operations, process, and activity at workplace provide the solid base to perform the system safety assessment.

Rigorous safety examination is accepted throughout the world for the safety assurance in process industries. The basic objectives of this work include the following points: (a) Record and Document incidents based on routine process, operation, and storage area for a particular duration of time.

(b) Generate a record and provide recognized form of incidents categorization based on the impact of same on man and machine.

(c) Provide an understanding of the causes by analyzing time between occurrences of each incident categories.

(d) Facilitate in decision making on action needed to increase the time between occurrences of incidents.

(e) Examine the system and subsystem of oil refinery critically for hazard identification and its evaluation.

This work considers two standard oil refineries in the different industrial belt of India. The refineries are designed to process Arab Mix crude and have the facility to process other types of Middle East crudes also.

\section{Literature Review}

In the area of system safety assessment and hazard evaluation many researchers contribute in mass to highlight the key 
elements. A lot of research work has been observed in the past focusing on the topic. Most of the literature survey concern to the topic has been complied. Since the area of research is broad, many parameters and their interpretation were assessed. The literature survey is the basis of problem formulation and selection of the present study. Some important contributions of different researcher in safety management systems are well tried and the details on the same are given below.

An author presented an IT based safety management system containing procedure safety standards and checklist on how different task should be performed. Safety standard and work procedure shall be analyzed as part of communication within the organization as concluded by him [1]. A five-step framework was proposed by a researcher in one review on safety analysis, studies in the construction industry. Three groups of construction safety researchers were identified. This review identified and discussed research gaps and corresponding agenda which can serve as guidance for future construction safety research [2].

An author presents the new developed fuzzy QRAM model which intends to support construction companies to reduce occupational safety risks. QRAM model was designed based on the best academic and empirical knowledge about safety risk on the construction industry. The technique also provides the flexibility that is difficult to achieve with other methods by taking in to account company's own historical chemical and process data [3]. A new risk evaluation method for oil storage tank based on the theory of two types of hazards has been developed in oil storage tanks possessing large amount of harmful substances and energy with great probability of accident release which can pose risk to personnel, equipment facilities, and environment. Firstly the two types of hazard inherent and controllable in oil tank zone were identified, analyzed, and classified. Secondly inherent hazards of oil storage tank zones are quantitatively evaluated by the major hazards, method which is conducted on the possibility and severity of accidents [4]. A discussion is observed in the development of new approach of inherent safety assessment called numerical descriptive inherent safety technique (NuDIST) This new methodology uses numerical assessment and can overcome the limitations inherent in the Index based methods and provides insights into the effect of safety parameters like temperature, Pressure, Heat of reaction, Process Inventory, Flammability, Explosiveness, and reactivity for the petrochemical industry [5]. Two authors presented a method in which time dependent events and time dependent probabilities of fatality are modeled by means of Monte Carlo Simulation method. They used realistic example from the offshore industry and obtained the results [6]. A researcher extended a survey on safety and proposed model of safety inspection. The parameters in model include main task of safety inspection such as general assignment of safety inspectors, high complexity, use of check list decision making, and performance feedback. This model provides a framework for the development of strategies to support the safety inspectors [7].

An informative assessment of fuel load survey methodologies and its impact on fire load data has been provided.
This study seeks to establish a structured approach to validate different fuel load survey mythologies and to enhance and develop guidance on means to correlate the fire load developed using those methodologies. Statically analyses have been performed using probability density function of lognormal distribution which is given by

$$
F(q)=\frac{1}{q \sigma \sqrt{2 \pi}} e^{-(1 / 2)(\ln q-\mu / \sigma)},
$$

where the domain $0 \leq q<+\infty$ and $\sigma>0, \mu<0$.

Extreme value distributions were also plotted using general, Gumbel, and Weibull distribution to provide better fit as compared to lognormal distribution. The probability density function of Gumbel is given by

$$
F(q)=\frac{1}{\beta} e^{-(q-\mu / \beta)} e^{-e-(q-\mu / \beta)},
$$

where domain $0<q<+\infty$.

The probability density function of Weibull distribution is given by

$$
F(q)=\frac{q}{\beta}\left(\frac{q}{\beta}\right)^{\alpha-1} \exp \left(-\left(\frac{q}{\beta}\right) \alpha\right),
$$

where domain $0 \leq q<+\infty[8]$.

Researchers also discussed the issue "effect on safety using safety standards in major hazard industries." They showed that the use of safety standard does not always give the expected effect on safety, as the implementation of safety standards for some measures can reduce the investment [9]. Authors presented a new method for optimizing the design of storage plants and minimizing the risk by calculating the ideal number of tanks and improving the way in which money was invested in safety. The probability of accident occurrence per storage unit will be calculated using basic principles of statistics. If $n$ is the number of unit in facility and $n f$ is the number of unit that suffer similar accidents at the same time then the probability of occurrence as independent event will be

$$
P=\left(\frac{1}{n}\right)^{n f} .
$$

Overall cost of accident will be estimated as

$$
C_{T}=C_{H}+C_{\text {str }}+C_{E}
$$

where $C_{H}$ is the Aug cost causing the death of human, $C_{\text {str }}$ the cost of consequences to housing structure, and $C_{E}$ the cost of equipment.

The risk associated with storage facility, the following causation can be used.

$$
\gamma(n)=\sum_{n f=1}^{n}\left[C_{n}^{n f} \cdot C_{T(n f)} \cdot f \cdot P_{(n f)}\right]
$$

also $C_{n}^{n f}=n ! / n f !(n-n f) ![10]$

With few example the usefulness and benefit of model calculation of electrostatic phenomena for the assessment 
of electrostatic ignition hazards were demonstrated. They include Silo filling and assessment of occurrences of cone discharge, calculation of capacitances of screw and flanges for assessment of earthling and bonding requirements, influence of sample geometry on the surface resistance, and resistivity and assessment of requirements of plastic hoses with a metal spiral for pneumatic transfer of powders [11]. Authors presented a study to assess the risk of fire and explosion in ISO max unit of Tehran oil refineries and study the influences of the controlling methods. The important process subunits in oil refineries were identified based on important affecting parameters such as process pressure, temperature, and material valve. The fire and explosion Index for each subunit was calculated. The results revealed that 6 subunits out of 8 had severe fire and explosion risk. A case study of gas turbine compressor system was analyzed using above approach [12]. Researchers presented a case study for the Greek public electric power provider for developing a new alternative system safety assessment from work in the work sites; this alternative safety assessment technique includes a stochastic and a deterministic approach. The incidents/accidents record of a 17-year period of 1993-2009 in the Greek public power corporation were analyzed using this alternative assessment approach. They highlight classification of system safety assessment according to stochastic approach [13]. Authors proposed a new safety analysis approach of MFM-HAZOP and applied it to the oil field united station. The subsystem of oil dehydration was analyzed by this approach and they prepared flow model construction, casual tree establishment, and the variance analysis of the individual nodes [14].

SDG-HAZOP method was introduced into safety evaluation by other authors for explosives production line. Hazard factors in a typical production line of emulsion explosives were identified after analyzing the whole process. Then the key variable and relationship were listed based on evaluation unit division. SDG-HAZOP qualitative model was developed by which automatic reasoning and analysis were conducted. Compared with the data of emulsion explosive production site and the experience of experts, it proved that SDG-HAZOP method was an efficient method to express almost all dangerous factors and negative consequences [15]. Researchers assumed hazardous material road transport was hot issue of societal public safety and was extremely important to quickly respond to and rescue emergency accident. Fire hazard characteristics were identified and analyzed on the leakage scenario and method of determination of accident emergency regions and a systematic frame work of emergency response was proposed [16]. Authors also applied preventive and protective method for system safety assessment called hazard and operational study. The method was demonstrated with various key words and parameter at fatty acid unit of Golnar oil refinery, Tehran, in order to study the consequences of major gas leakage incident. The risk assessment simulation of VCE accident caused by gas leaked from LPG tank was performed [17]. Researchers presented a comparison study on qualitative and quantitative assessments for urban natural gas pipe line network. The qualitative method was comprised of an Index System and the quantitative method consists of a probability assessment, a consequences analysis, and a risk evaluation. Two sample urban natural gas pipeline networks are used to demonstrate these assessments. The selection of indices is based on the statistical analysis of data base and the calculation is according to the reliability Engineering theory [18]. Authors also proposed a methodology for evaluation and monitoring of recurring hazards in underground coal mine. They assessed the coal mines incidents of 10 years' duration. Their model steps include collection of incident occurrence date wise, categorization of incidents based on their impact on coal mines and its machinery, computation of time between occurrences which is equivalent to time between failures in reliability study, fitting of appropriate distribution for TBO data, and obtaining the parameters of distribution and interpret the results. The probability density function of Weibull distribution was fit appropriate for the proposed methodology [19]. A severity analysis of Indian coal mine accidents for 100 years was done by researchers considering total and serious accidents. An event evaluation algorithm was developed for this purpose. They develop the hazard rate function which includes the following steps:

(1) Collect date wise occurrence of incidents.

(2) Calculate time between occurrences for all incidents together and for each hazard group.

(3) Fit appropriate probability distribution function TBOS and estimate appropriate parameters.

(4) Obtain hazard for the particular pdf [20].

Authors also demonstrated an overview of 62 risk analysis methodologies of industrial plant. These methodologies were separated into three different phases which include identification, evaluation, and hierarchy. The input data for individual methodology grouped into seven categories which include plan or diagram, process and reaction, products, probability and frequencies, policy, environment, text, and historical knowledge. The methods were ranked into six classes based on the combination of four usual criteria which include qualitative, quantitative, deterministic, and probabilistic. The output data from individual method were also classified in to four classes which include management list, probabilistic, and hierarchy. The paper deals with the application fields and the important limitation of these methodologies. They highlight the difficulties in taking into account and suggesting most appropriate method [21].

\section{Materials and Methods}

This chapter refers to the incident data collection methodology opted by the author and use of incident statistics in forecasting and development of hazard rate function. The development of hazard rate function and probability density function are based on five-year incident data collected by the author. The Weibull analysis has been performed for learning from the analysis of aggregate incident data.

3.1. Types of Accident and Incident Data. Author accessed the different documented data at the different workplaces of two oil refineries. Most commonly used distinction between 
accidents and incidents is that accidents have a specific outcome while incidents have no outcome such as injuries, damage, fire, and leakage in an organization. Accident includes any undesired circumstances which give rise to ill-health, damage to property, plant, products, production loss, and increased liabilities. Incident includes all undesired circumstances which could cause accidents; it is preferable to think incidents as part of single, much larger group of undesired events which leads to accident.

3.2. Collection of Accident and Incident Data. Two oil refineries of our country have been considered for this work and author had completed one-month and two-week vocational training in these oil refineries for the collection of accident and incident data. The major sources of accident and incident data within these oil refineries during vocational training include Accidents Report, Accident/Incident Record, Accident notification, and investigating report. In these oil refineries management system follows the chronology of an accident and the author identified the following source to accomplish the same.

(a) The person, who sustains the injury, or someone else, reports that an accident/incident has happened, usually in an online system which is assessable to all EHS professional.

(b) The EHS professional, to whom the accident/incident is reported, makes a written record of the salient points, usually in a risk register form.

(c) The accident is investigated and, if it is sufficiently serious, is reported to the relevant state authority which is Director, Industrial Health \& Safety of the State.

(d) The EHS professional who investigates the accident writes a report on his or her findings, to which are added any suggestions for remedial action.

(e) The EHS professional who investigates the accident reports back to those involved in the outcome of the investigation and the action to be taken.

The vocational training follows the three major steps in collecting accident and incident data of the oil refineries. First step involves the critical examination of all reported accidents and incidents available with the EHS department of oil refineries. The second step for checking of nonreporting incident and accident was beginning. Personal interviews with people who are likely to have experience or knowledge of the accident or incident were commenced. People are more willing to talk about accident or incident they did not report if they are confident that there will be no adverse consequences as a result of their revelations. The author has carried out an appropriate sample of interviews which make a reasonable accurate assessment of the proportion of accidents or incident which is going unreported. Inspections of locations where incident/accident took place was done by author during these interviews and one set of incident record is kept ready for cross checking the statement given by individual person. Sufficient data was collected by us from 2010 to 2015 for analysis of incident/accident within these oil refineries.
3.3. Classification of Accident/Incident Data. Incident type has been arranged date wise from last five years in risk register of the concerned oil refineries. A short description about the incident/accident was found and based on which the type of incident/accident was categorized as described in Table 1. The severity level was broadly classified into different aspects the first in terms of harm to personnel and second in terms of plant damage and loss production. The four major significant scales have been decided to be the severity level of individual incident which took place. The detailed description on these scales of consequences is given below.

We have set up a scale of harm to personnel based on Table 1 as follows:

Minor: reportable but nondisabling injuries causing over 3 days of absence.

Critical: disabling injury or severe injury requiring extensive recovery and 1 in 10 chance of fatality.

Severe: critical injuries and possibly 1 fatality.

Catastrophic: one or more fatalities.

Also scale of plant damage and production loss based on Table 1 is as follows:

Minor: short-term loss of production.

Critical: damage to machines repairable in short time.

Severe: damage to plant, major repair costs, and serious loss of production.

Catastrophic: substantial damage to plant and potential loss of overall plant.

\subsection{Development of Probability Density Function and Hazard Rate Function}

3.4.1. Introduction to Weibull Distribution. The Weibull distribution is one of the most widely used lifetime distributions in reliability Engineering. It is a versatile distribution that can take on the characteristics of other types of distributions, based on the value of the shape parameter and scale parameter. To apply Weibull distribution to the available data from oil refinery we have to categories the data in four major categories and the estimates of the parameters of the Weibull distribution can be found graphically via probability plotting paper, using least squares (rank regression) analysis.

3.4.2. Estimation of the Weibull Parameters. The steps for determining the parameters of the Weibull distribution representing the data, using probability plotting, are first rank the time between occurrences in ascending order for all four major categories. The method of probability plotting takes pdf of the distribution and attempts to linearize it by employing a specially constructed paper. The following sections illustrate the steps in this method using 2 parameter Weibull distributions.

(a) Linearize the unreliability function.

(b) Construct the probability plotting paper

(c) Determine the $X$ and $Y$ positions of the plot points. 
TABLE 1: The main types of accident and incident data.

\begin{tabular}{|c|c|c|c|c|}
\hline Quality & Environment & Injuries & Health & $\begin{array}{l}\text { Asset damage and } \\
\text { other losses }\end{array}$ \\
\hline Customer complaints & Spillage & $\begin{array}{c}\text { Injuries to employees at } \\
\text { work }\end{array}$ & Sickness absence & $\begin{array}{c}\text { Damage to } \\
\text { organizations assets }\end{array}$ \\
\hline $\begin{array}{l}\text { Product non } \\
\text { conformances }\end{array}$ & Emissions above consent levels & Injuries to others at work & Chronic illness & $\begin{array}{l}\text { Damage to other } \\
\text { people's assets }\end{array}$ \\
\hline $\begin{array}{l}\text { Service non } \\
\text { conformances }\end{array}$ & Discharges above consent levels & Injuries during travel & Sensitization & $\begin{array}{l}\text { Interruptions to } \\
\text { production }\end{array}$ \\
\hline & & $\begin{array}{l}\text { Injuries arising from } \\
\text { unsafe products }\end{array}$ & & $\begin{array}{l}\text { Damage arising from } \\
\text { unsafe products }\end{array}$ \\
\hline
\end{tabular}

Adapted from [22].

3.5. Constructing the Paper. The next task is to construct the Weibull probability plotting paper with the appropriate $y$ and $x$-axes. The $x$-axis transformation is simply logarithmic of time between occurrence (TBO) and $y$-axis is a bit more Complex requiring a double log reciprocal transformation as

$$
\begin{aligned}
& y=\ln \left(\ln \left(\frac{1}{1-\text { median rank of } y}\right)\right) \\
& x=\ln (\mathrm{TBO}) .
\end{aligned}
$$

3.6. Scale and Shape Parameter Estimation. Shape and scale parameter are hereby estimated using rank regression on $y$ axis, assuming that the data follow the 2 parameter Weibull distributions.

The least squares parameter estimation method provides following equation for calculation of shape and scale parameter. The detailed calculations for minor incidents for $N=662$ are as follows:

$$
\begin{gathered}
\widehat{b}=\frac{\sum_{i=1}^{662}(\ln t i) y i-\left(\sum_{i=1}^{662} \ln t i\right)\left(\sum_{i=1}^{662} y i\right) / 662}{\sum_{i=1}^{662}(\ln t i)^{2}-\left(\sum_{i=1}^{662} \ln t i\right)^{2} / 662} \\
\widehat{b}=\frac{833.598-(227.5682)(-380.8489) / 662}{1141.255-(277.5682)^{2} / 662} \\
\widehat{b}=\frac{833.598-130.92}{1141.255-78.2285}=\frac{703.598}{1063} \\
\widehat{b}=0.6618 \\
\widehat{a}=\frac{\sum_{i=1}^{662} y_{i}}{662}-\widehat{b} \frac{\sum_{i=1}^{662} \ln t i}{662} \\
\widehat{a}=\frac{(0.6616 * 227.5682)}{662} \\
\widehat{a}=-0.5753-0.2274 \\
\widehat{a}=-0.8027 \\
\hat{\eta}=0.6618 \\
\widehat{b}=\hat{a} / \widehat{b}
\end{gathered}
$$

$$
\begin{gathered}
\widehat{\eta}=e-\left(-\frac{0.8027}{0.6618}\right) \\
\widehat{\eta}=e^{1.2130} \\
\widehat{\eta}=3.363
\end{gathered}
$$

Shape parameter for Minor Incident $\widehat{\beta}=0.6618$

Scale parameter for Minor Incident $\widehat{n}=3.363$.

Weibull paper for minor incidents, as shown in Figure 1, gives interpretive clues about the minor incidents category happening. The estimated slope of curve using rank regression is 0.669 and it is less than 1 . This is often referring to as an infant mortality failure mode. It includes inadequate working conditions, unsafe act, and unsafe conditions at work place.

The least squares parameter estimation method provides following equation for calculation of shape and scale parameter. The detailed calculations for critical incidents for $N=133$ are as follows:

$$
\begin{aligned}
\widehat{b} & =\frac{\sum_{i=1}^{133}(\ln t i) y_{i}-\left(\sum_{i=1}^{133} \ln t i\right)\left(\sum_{i=1}^{133} y i\right) / 133}{\sum_{i=1}^{133}(\ln t i)^{2}-\left(\sum_{i=1}^{133} \ln t i\right)^{2} / 133} \\
\widehat{b} & =\frac{109.0762+(217.1707)((-75.7878) / 133)}{654.5238-(217.1707)^{2} / 133} \\
\widehat{b} & =\frac{109.0762+123.75}{654.5238-354.6098} \\
\widehat{b} & =\frac{232.8262}{299.914}=0.7763 \\
\widehat{a} & =\frac{\sum_{i=1}^{133} y_{i}}{133}-\widehat{b} \frac{\sum_{i=1}^{133} \ln t i}{133}=\frac{-75.7878}{133}-0.7763 \\
& * \frac{217.1707}{133}=-0.5698-1.2675 \\
\widehat{a} & =1.8337 \\
\widehat{\beta} & =\widehat{b}=0.7763 \\
\widehat{\eta} & =e^{-\widehat{a} / \widehat{b}}
\end{aligned}
$$




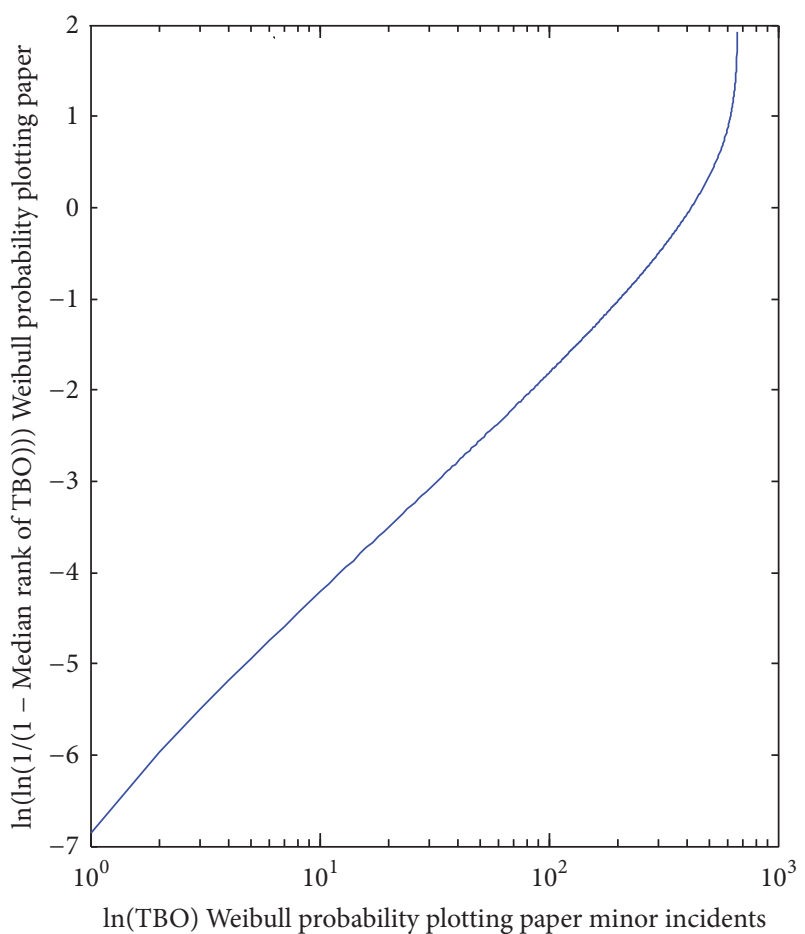

FIGURE 1: Weibull paper for minor incident 2010 to 2015.

$$
\begin{aligned}
& \widehat{\eta}=e^{-}\left(\frac{-1.8337}{0.7763}\right) \\
& \widehat{\eta}=e^{2.366} \\
& \widehat{\eta}=10.6638
\end{aligned}
$$

Share parameter for Critical Incident $\widehat{\beta}=0.7763$

Scale parameter for Critical Incident $\widehat{n}=10.6638$.

Weibull paper for critical incidents as shown in Figure 2 gives interpretive clues about the critical incidents category happening. The estimated slope of curve using rank regression is 0.7763 and it is less than 1 . This is often referring to an infant mortality failure mode. It includes maintenance error, noncompilation of safe operating procedure, and improper installation of components.

The least squares parameter estimation method provides the following equation for calculation of shape and scale parameter. The detailed calculations for severe incidents for $N=39$ are as follows:

$$
\begin{gathered}
\widehat{b}=\frac{\sum_{i=1}^{39}(\ln t i) y_{i}-\left(\sum_{i=1}^{39} \ln t i\right)\left(\sum_{i=1}^{39} y i\right) / 39}{\sum_{i=1}^{39}(\ln t i)^{2}-\left(\sum_{i=1}^{39} \ln t i\right)^{2} / 39} \\
\widehat{b}=\frac{1.9959-(115.2579)((-21.7429) / 39)}{422.9738-(115.2579)^{2} / 39}
\end{gathered}
$$

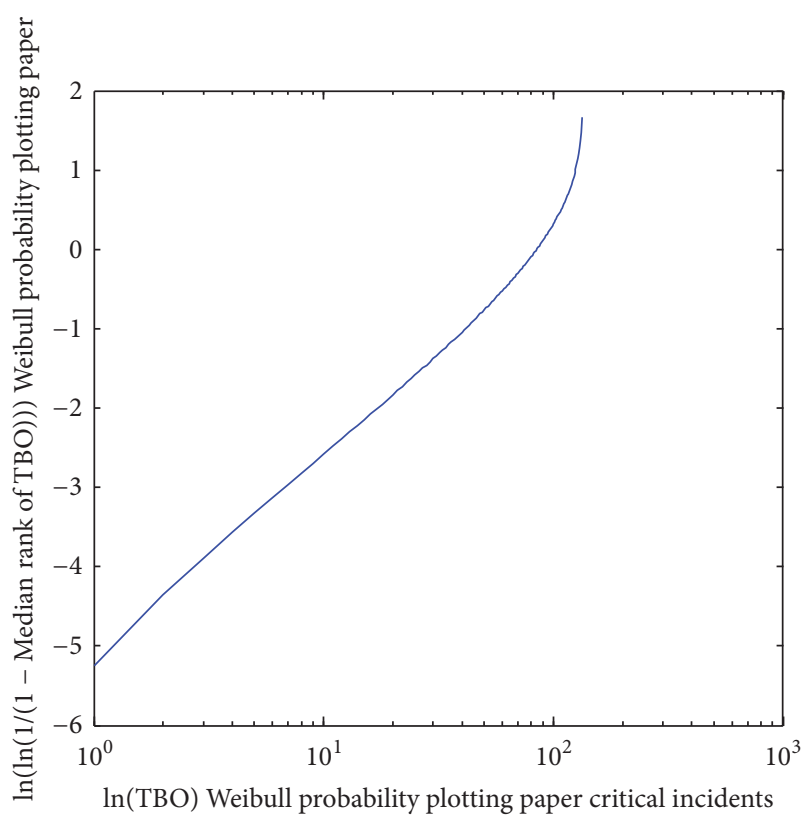

FIGURE 2: Weibull paper for critical incident 2010 to 2015.

$$
\begin{gathered}
\widehat{b}=\frac{1.9959+64.2574}{422.9738-340.6252} \\
\widehat{b}=\frac{66.2533}{82.3485}=0.8054 \\
\widehat{a}=\frac{\sum_{i=1}^{39} y i}{39}-\widehat{b} \frac{\sum_{i=1}^{39} \ln t i}{39} \\
\widehat{a}=\frac{-21.7429}{39}-0.8045 *\left(\frac{115.2579}{39}\right) \\
\widehat{a}=-0.5575-2.3775 \\
\widehat{a}=2.9350 \\
\widehat{\beta}=\hat{b}=0.8045 \\
\widehat{\eta}=e^{-\widehat{a} / \widehat{b}} \\
\hat{\eta}=e^{-}\left(\frac{-2.9350}{0.8045}\right) \\
\hat{\eta}=e^{3.6482} \\
\widehat{\eta}=38.4065
\end{gathered}
$$

Shape parameter for Severe Incident $\widehat{\beta}=0.8054$

Scale parameter for Severe Incident $\widehat{n}=38.4065$.

Weibull paper for severe incidents as shown in Figure 3 gives interpretive clues about the severe incidents category happening. The estimated slope of curve using rank regression is 0.8054 and it is less than 1 . This is often referring to an infant mortality failure mode. It includes maintenance error, 


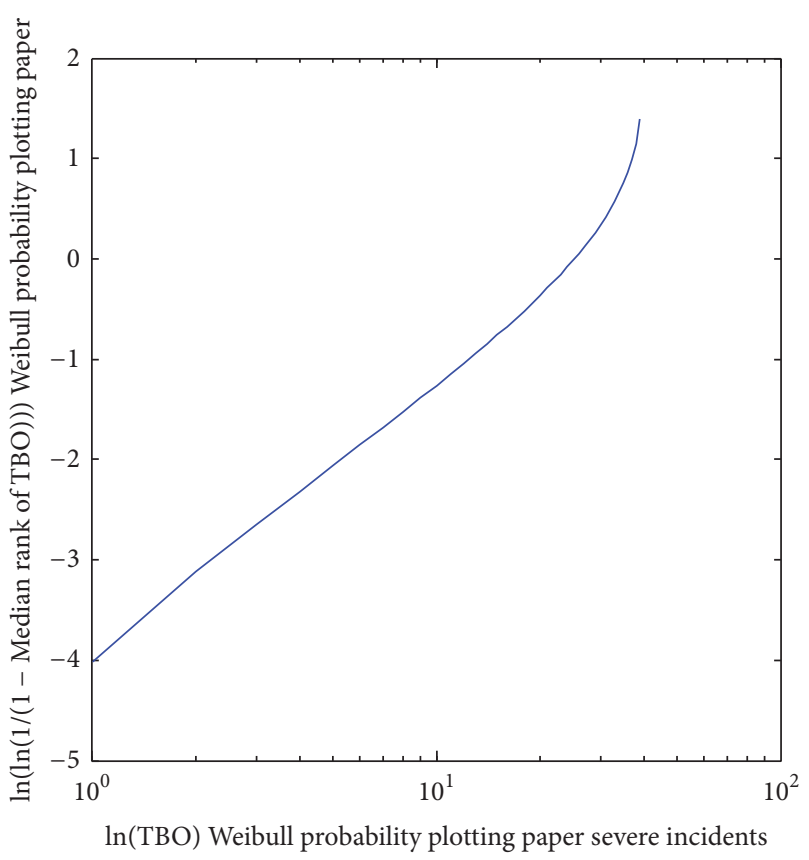

FIGURE 3: Weibull paper for severe incident 2010 to 2015.

noncompilation of safe operating procedure, and improper installation of components.

The least squares parameter estimation method provides the following equation for calculation on shape and scale parameter. The detailed calculations for catastrophic incidents for $N=7$ are as follows:

$$
\begin{aligned}
& \widehat{b}=\frac{\sum_{i=1}^{7}(\ln t i) y_{i}-\left(\sum_{i=1}^{7} \ln t i\right)\left(\sum_{i=1}^{7} y i\right) / 7}{\sum_{i=1}^{7}(\ln t i)^{2}-\left(\sum_{i=1}^{7} \ln t i\right)^{2} / 7} \\
& \widehat{b}=\frac{5.6829-(31.6077)((-3.5564) / 7)}{166.817-(31.6077)^{2} / 7} \\
& \widehat{b}=\frac{5.6829+16.0585}{166.817-142.7209} \\
& \widehat{b}=\frac{10.3756}{24.0961}=0.4305 \\
& \widehat{a}=\frac{\sum_{i=1}^{7} y i}{7}-\widehat{b} \frac{\sum_{i=1}^{7} \ln t i}{7} \\
& \widehat{a}=\frac{-3.5564}{7}-0.4305 *\left(\frac{31.6077}{7}\right) \\
& \widehat{a}=-0.5080-1.9438 \\
& \widehat{a}=2.4518 \\
& \widehat{\beta}=\widehat{b}=0.4305 \\
& \widehat{\eta}=e^{-\widehat{a} / \widehat{b}} \\
& \widehat{\eta}=e^{-}\left(\frac{-2.4518}{0.5080}\right)
\end{aligned}
$$

$$
\begin{gathered}
\widehat{\eta}=e^{4.8} \\
\widehat{\eta}=124.77
\end{gathered}
$$

Shape parameter for Catastrophic Incident $\widehat{\beta}=0.4305$

Scale parameter for Catastrophic Incident $\widehat{n}=124.77$.

Weibull paper for catastrophic incidents as shown in Figure 4 gives interpretive clues about the catastrophic incidents category happening. The estimated slope of curve using rank regression is 0.4305 and it is less than 1 . This is often referring to an infant mortality failure mode. It includes human errors, operational uncontrolled, and lack of training.

The least squares parameter estimation method provides the following equation for calculation on shape and scale parameter. The detailed calculations for all incidents for $N=$ 839 are as follows:

$$
\begin{gathered}
\widehat{b}=\frac{\sum_{i=1}^{839}(\ln t i) y i-\left(\sum_{i=1}^{839} \ln t i\right)\left(\sum_{i=1}^{839} y i\right) / 839}{\sum_{i=1}^{839}(\ln t i)^{2}-\left(\sum_{i=1}^{839} \ln t i\right)^{2} / 839} \\
\widehat{b}=\frac{1069.634-(131.06)(-482.97) / 839}{1242.06-(131.06)^{2} / 839} \\
\widehat{b}=\frac{1069.63+75.44}{1242.06-20.47}=\frac{1145.07}{1221.58} \\
\widehat{b}=0.937 \\
\hat{a}=\frac{\sum_{i=1}^{839} y_{i}}{839}-\widehat{b} \frac{\sum_{i=1}^{839} \ln t i}{839} \\
\widehat{a}=\frac{-482.97}{839}-\frac{(0.937 * 131.06)}{839} \\
\widehat{a}=-0.575-0.1463 \\
\widehat{a}=-0.7213 \\
\widehat{\beta}=\widehat{b}=0.937 \\
\hat{\eta}=e^{-\widehat{a} / \hat{b}} \\
\hat{\eta}=e-\left(-\frac{0.7213}{0.937}\right) \\
\hat{\eta}=e^{0.7699} \\
\hat{\eta}=2.159
\end{gathered}
$$

Shape parameter for all Incident $\widehat{\beta}=0.937$

Scale parameter for Catastrophic all Incident $\widehat{n}=2.159$.

Weibull paper for all incidents as shown in Figure 5 gives interpretive clues about the all incidents category happening. The estimated slope of curve using rank regression is 0.937 and it is very near to 1 . This is often referring to original design deficiencies at work place, insufficient redundancy, and unexpected incident happening. This would result in constant incidents happening condition. 


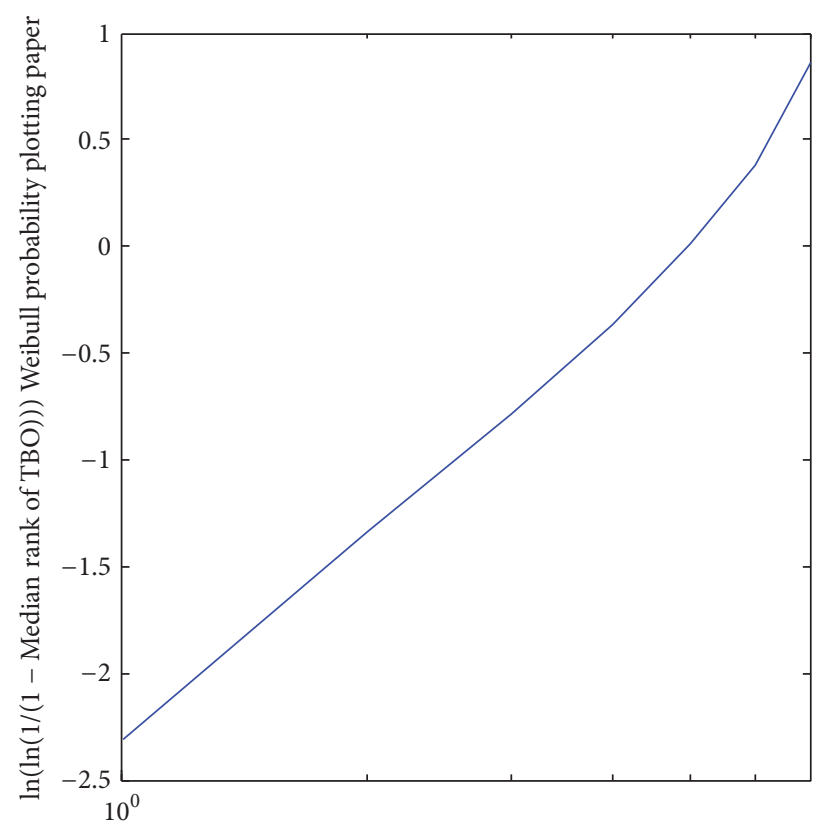

$\ln (\mathrm{TBO})$ Weibull probability plotting paper catastrophic incidents

FIgURE 4: Weibull paper for catastrophic incident 2010 to 2015.

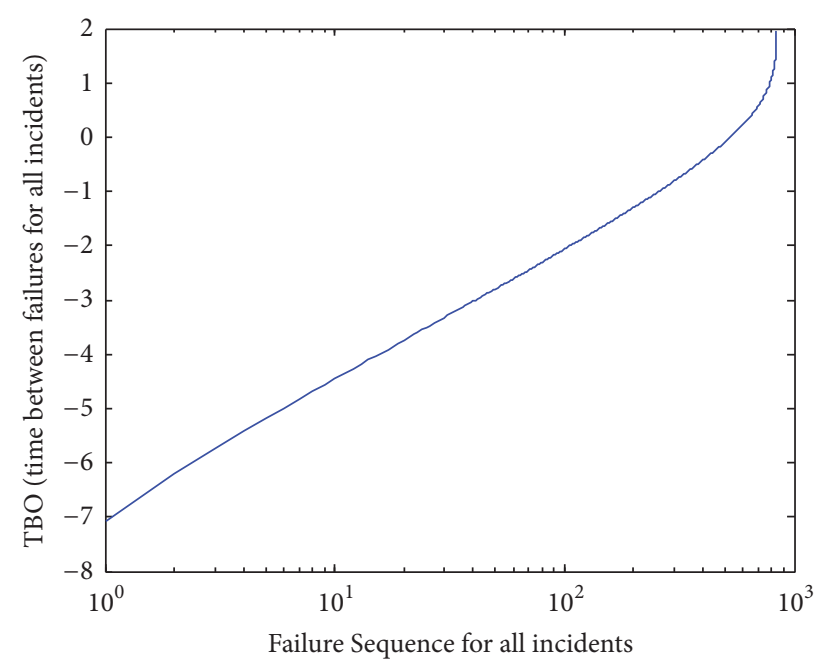

Figure 5: Weibull paper for all incident 2010 to 2015.

\section{Result and Discussion}

A repetitive incident occurrence is one of the major indicators of safety within the plant. A regressions analysis has been performed on developing procedure for estimating the time between occurrences of different incident categories; we observed two categories in first category predictions based on individual incident category failure rates wherever in second the predictions are based on probability distribution function. The hazard function is defined as the limit of the occurrence rate of incident as the interval approaches zero. Thus the hazard function is the instantaneous failure for nonoccurrences of any incident. The importance of the hazard function is that it indicates the change in the failure rate over the time period in nonoccurrence of any incident. The hazard function derived by considering time between occurrences of each incident for a time span of 5 years' Weibull failure density function is calculated based on Weibull estimators as shape parameter $(\beta)$ and scale parameter $(\eta)$. The calculation and estimation of Weibull parameter were done by probability plotting. by

Weibull Probability Distribution function (PDF) is given

$$
F(x)=\left(\frac{\beta}{\eta}\right)\left(\frac{x}{\eta}\right)^{\beta-1} \exp \left(\frac{-x}{\eta}\right)^{\beta}
$$

and Hazard function is given by:

$$
h(x)=\left(\frac{\beta}{\eta}\right)\left(\frac{x}{\eta}\right)^{\beta-1} .
$$

Put the value for all incidents as $\beta=0.937, \eta=2.159,(\beta / \eta=$ $0.433), \beta-1=-0.063$.

We have

$$
\begin{aligned}
& f(x)_{\text {All incident }}=0.45 x^{-0.063} \exp (-0.46 x)^{0.937} \\
& h(x)_{\text {All incident }}=0.45 x^{-0.063} .
\end{aligned}
$$

Put the value for minor incidents as $\beta=0.6618, \eta=3.363$, $(\beta / \eta=0.196), \beta-1=-0.03382$.

$$
\begin{aligned}
& f(x)_{\text {Minor incident }}=0.295 x^{-0.3382} \exp (-0.29 x)^{0.6618} \\
& h(x)_{\text {Minor incident }}=0.29 x^{-0.3382} .
\end{aligned}
$$

Put the value for critical incidents as $\beta=0.7763, \eta=10.66$, $(\beta / \eta=0.072), \beta-1=-0.223$.

$$
\begin{aligned}
& f(x)_{\text {Critical incident }}=0.00074 x^{-0.223} \exp (-0.09 x)^{0.7763} \\
& h(x)_{\text {Critical incident }}=0.00074 x^{-0.223} .
\end{aligned}
$$

Put the value for severe Incidents as $\beta=0.8045, \eta=38.40$, $(\beta / \eta=0.020), \beta-1=-0.1955$.

$$
\begin{aligned}
& f(x)_{\text {Severe incident }}=0.4 x^{-0.195} \exp (-0.26 x)^{0.8045} \\
& h(x)_{\text {Severe incident }}=0.4 x^{-0.195} .
\end{aligned}
$$

Put the value for catastrophic incidents as $\beta=0.4305, \eta=$ 124.77, $\left(\beta / \eta=3.4 * 10^{-3}\right), \beta-1=-0.569$.

$$
\begin{aligned}
& f(x)_{\text {Catastrophic incident }} \\
& \quad=0.053 x^{-0.569} \exp (-0.008 x)^{0.4305} \\
& h(x)_{\text {Catastrophic incident }}=0.053 x^{-0.569} .
\end{aligned}
$$

\section{Conclusions and Recommendations}

5.1. Conclusions. This work firstly presented the incident data collection resources and secondly the application of reliability tool in its statics for the single objective of system safety assessment. The conclusion of the work may be summarized in the following way: 
TABLE 2: Output of Weibull analysis as probability distribution function and Hazard Rate Function.

\begin{tabular}{lccccc}
\hline S. Number & $\begin{array}{c}\text { Type of } \\
\text { incident }\end{array}$ & $\begin{array}{c}\text { Value of } \\
B \text { (shape } \\
\text { parameter })\end{array}$ & $\begin{array}{c}\text { Value of } \\
\eta \text { (scale } \\
\text { parameter })\end{array}$ & $\begin{array}{c}\text { Probability Distribution function } \\
f(x)\end{array}$ & $\begin{array}{c}\text { Hazard Rate } \\
\text { Function } \\
h(x)\end{array}$ \\
\hline$(1)$ & All & 0.937 & 2.159 & $0.45 x^{-0.063} \exp (-0.46 x)^{0.937}$ & $0.45 x^{-0.063}$ \\
$(2)$ & Minor & 0.6618 & 3.363 & $0.295 x^{-0.3382 \exp (-0.29 x)^{0.6618}}$ & $0.29 x^{-0.3382}$ \\
$(3)$ & Critical & 0.7763 & 10.66 & $0.00074 x^{-0.223} \exp (-0.09 x)^{0.7763}$ & $0.00074 x^{-0.223}$ \\
$(4)$ & Severe & 0.8045 & 38.40 & $0.4 x^{-0.195} \exp (-0.26 x)^{0.8045}$ & $0.4 x^{-0.195}$ \\
$(5)$ & Catastrophic & 0.4305 & 124.77 & $0.053 x^{-569} \exp (-0.008 x)^{0.4305}$ & $0.053 x^{-0.569}$ \\
\hline
\end{tabular}

(a) The manmade disaster or major industrial accidents as mentioned by Saleh et al. [23] are a particular class of incident that have common patterns in their making and they can be analyzed with improved system safety assessment techniques as a performed by this research.

(b) The major industrial accidents are in the making over long incubation periods; their causes extend deep into the past as chain of discrepant incidents develop and accumulate unnoticed until a major catastrophic accident is released based on probability distribution function and hazard rate function as shown in Table 2

(c) The occurrence of major accident cannot take place by purely technical problem but management and organizational matters are key contributors to the accident. Although, system safety assessment is based on systematic risk assessment and the continuous management of the safety of plant through operational control and training.

(d) The system safety assessment of any organization can be accurately achieved based on the incident occurrences within the plant community. The documentation and record on incidents within the particular duration of time support the research in precise forecasting of their reoccurrences in near future as indicated by shape parameter $(\beta)$ and scale parameter $(\eta)$ in Table 2 of Weibull analysis results.

(e) The categorization in incidents by using minor, critical, severe, and catastrophic criteria helps in the assessment of incident severity with respect to plant machinery damage and loss of human life and injuries.

(f) In this research we provide an event evaluation algorithm using Weibull distribution for development probability density function and hazard rate function based on incident occurrence in oil refinery. Rank regression method as described by Marhavilas and Koulouriotis [13] in stochastic approach is used for the shape and scale parameters estimation of Weibull distribution.

5.2. Recommendations. The study recommendations to the oil refineries are based on the critical safety assessment of different section of oil refinery which includes CDU, VDU, HDT, CRU, and NHT. The following recommendation may be incorporated for the improved safety management in the oil refineries:

(a) A detailed written report on incident occurrence shall be reviewed in presence of the people who are directly involved in repetitive type of incident.

(b) A comprehensive solution in lay out, operation, and process shall be investigated about either removal of the type of incident from the site or minimization of its impact.

(c) The incident recording and documentation shall be preserved with the evidence for the cooperation with statutory investigation and accurate system safety assessment.

(d) The time between occurrences of incidents may be increased if employer ensures the safety training of new employee.

(e) The type emergencies need to be clearly articulated and their potential impact on the site must be conveyed among plant community as well as local community.

\section{Competing Interests}

The authors declare that they have no competing interests.

\section{References}

[1] T. Wold and K. Laumann, "Safety Management Systems as communication in an oil and gas producing company," Safety Science, vol. 72, pp. 23-30, 2015.

[2] Z. Zhou, Y. M. Goh, and Q. Li, "Overview and analysis of safety management studies in the construction industry," Safety Science, vol. 72, pp. 337-350, 2015.

[3] A. Pinto, "QRAM a qualitative occupational safety risk assessment model for the construction industry that incorporate uncertainties by the use of fuzzy sets," Safety Science, vol. 63, pp. 57-76, 2014.

[4] J. Kang, W. Liang, L. Zhang et al., "A new risk evaluation method for oil storage tank zones based on the theory of two types of hazards," Journal of Loss Prevention in the Process Industries, vol. 29, no. 1, pp. 267-276, 2014.

[5] S. I. Ahmad, H. Hashim, and M. H. Hassim, "Numerical descriptive inherent safety technique (NuDIST) for inherent safety assessment in petrochemical industry," Process Safety and Environmental Protection, vol. 92, no. 5, pp. 379-389, 2014. 
[6] R. Bris, S. Medonos, C. Wilkins, and A. Zdráhala, "Timedependent risk modeling of accidental events and responses in process industries," Reliability Engineering and System Safety, vol. 125, pp. 54-66, 2014.

[7] K. Woodcock, "Model of safety inspection," Safety Science, vol. 62, pp. 145-156, 2014.

[8] E. Zalok and J. Eduful, "Assessment of fuel load survey methodologies and its impact on fire load data," Fire Safety Journal, vol. 62, pp. 299-310, 2013.

[9] E. B. Abrahamsen, F. Asche, and M. F. Milazzo, "An evaluation of the effects on safety of using safety standards in major hazard industries," Safety Science, vol. 59, pp. 173-178, 2013.

[10] E. J. Bernechea and J. A. Viger, "Design optimization of hazardous substance storage facilities to minimize project risk," Safety Science, vol. 51, no. 1, pp. 49-62, 2013.

[11] M. Glor and A. Pey, "Modelling of electrostatic ignition hazards in industry examples of improvements of hazard assessment and incident investigation," Journal of Electrostatics, vol. 71, no. 3, pp. 362-367, 2013.

[12] M. Javad Jafari, M. Zarei, and M. Movahhedi, "The credit of fire and explosion index for risk assessment of ISO-Max unit in an oil refinery," International Journal of Occupational Hygiene, vol. 4, pp. 10-16, 2012.

[13] P. K. Marhavilas and D. E. Koulouriotis, "Developing a new alternative risk assessment framework in the work sites by including a stochastic and a deterministic process: a case study for the Greek Public Electric Power Provider," Safety Science, vol. 50, no. 3, pp. 448-462, 2012.

[14] W. Mingdaa, C. Guominga, F. Jianmina, and L. Weijuna, "International symposium on safety science and engineering in China, 2012 (ISSSE-2012) safety analysis approach of MFMHAZOP and its application in the dehydration system of oilfield United Station," Procedia Engineering, vol. 43, pp. 437-442, 2012.

[15] Z. Jingyi and W. Liqiong, "Safety evaluation of emulsion explosives production line based on SDG-HAZOP," Procedia Engineering, vol. 45, pp. 144-151, 2012, Proceedings of the 2012 International Symposium on Safety Science and Technology.

[16] R. Changing, Y. Xiongjun, W. Jie, Z. Xin, and L. Jin, "Study on emergency response rank mode of flammable and explosive hazardous materials road transportation," Procedia Engineering, vol. 45, pp. 830-835, 2012.

[17] I. Mohammadfam, A. Sajedi, S. Mahmoudi, and F. Mohammadfam, "Application of Hazard and Operability Study (HAZOP) in Evaluation of Health, Safety and Environmental (HSE) hazards," International Journal of Occupational Hygiene, vol. 4, no. 2, pp. 17-20, 2012.

[18] Z. Y. Han and W. G. Weng, "Comparison study on qualitative and quantitative risk assessment methods for urban natural gas pipeline network," Journal of Hazardous Materials, vol. 189, no. 1-2, pp. 509-518, 2011.

[19] V. V. Khanzode, J. Maiti, and P. K. Ray, "A methodology for evaluation and monitoring of recurring hazards in underground coal mining," Safety Science, vol. 49, no. 8-9, pp. 1172-1179, 2011.

[20] J. Maiti, V. V. Khanzode, and P. K. Ray, "Severity analysis of Indian coal mine accidents-a retrospective study for 100 years," Safety Science, vol. 47, no. 7, pp. 1033-1042, 2009.

[21] J. Tixier, G. Dusserre, O. Salvi, and D. Gaston, "Review of 62 risk analysis methodologies of industrial plants," Journal of Loss Prevention in the Process Industries, vol. 15, no. 4, pp. 291-303, 2002.

[22] A. J. Boyle, "The collection and use of accident and incident data," in Safety at Work, pp. 263-303, Elsevier, 6th edition, 2003.
[23] J. H. Saleh, K. B. Marais, E. Bakolas, and R. V. Cowlagi, "Highlights from the literature on accident causation and system safety: review of major ideas, recent contributions, and challenges," Reliability Engineering and System Safety, vol. 95, no. 11, pp. 1105-1116, 2010. 

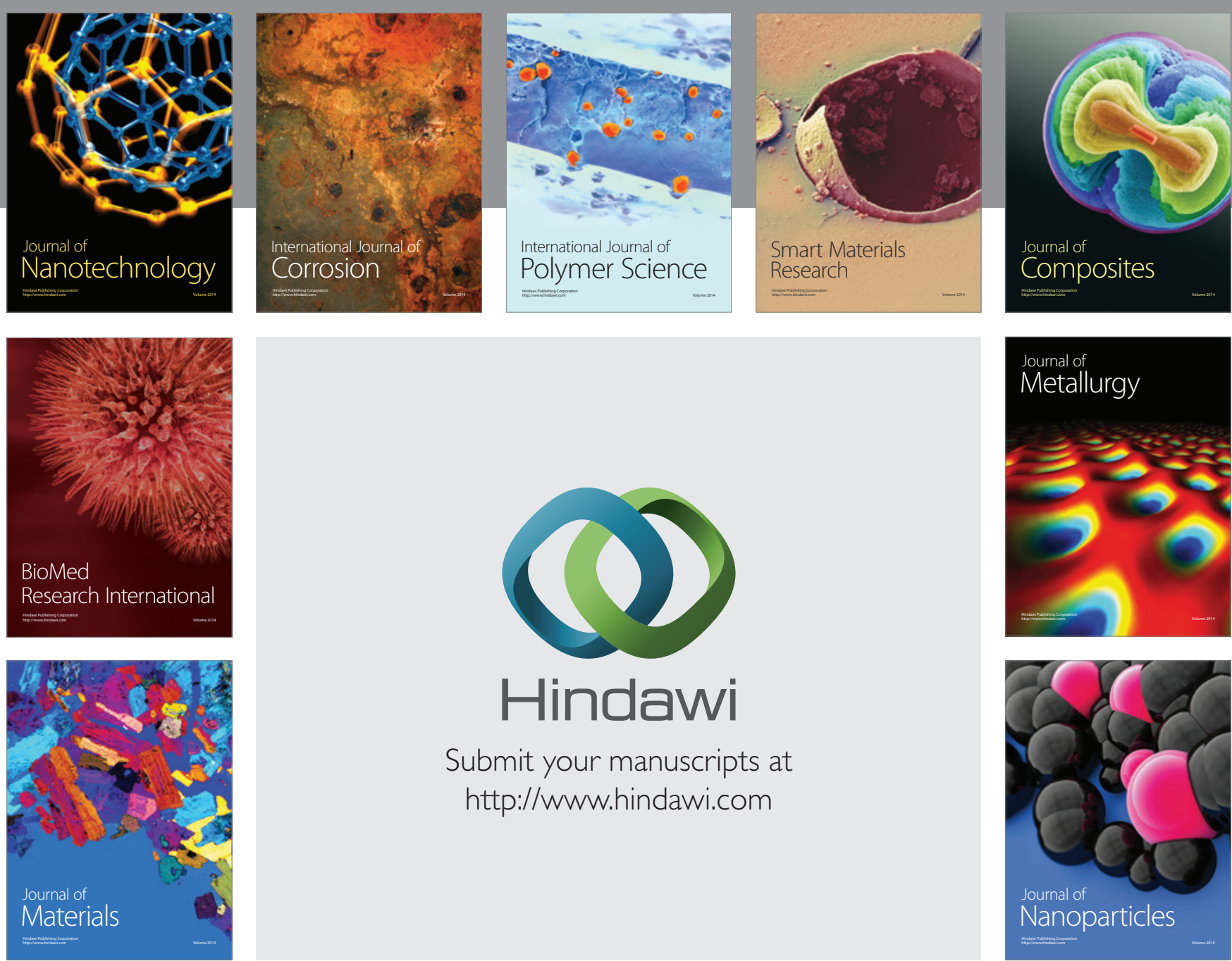

\section{Hindawi}

Submit your manuscripts at

http://www.hindawi.com

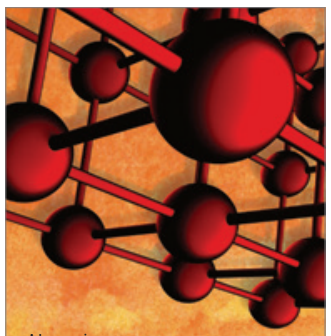

Materials Science and Engineering
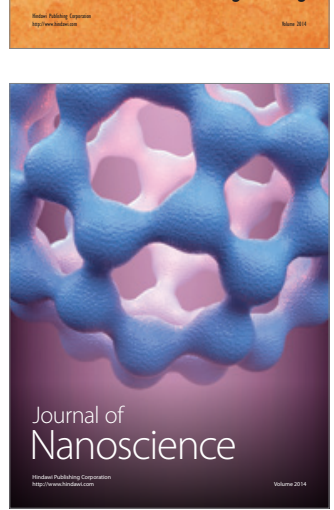
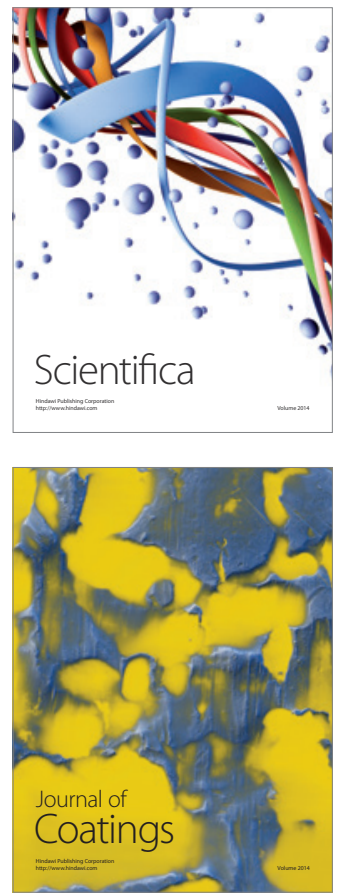
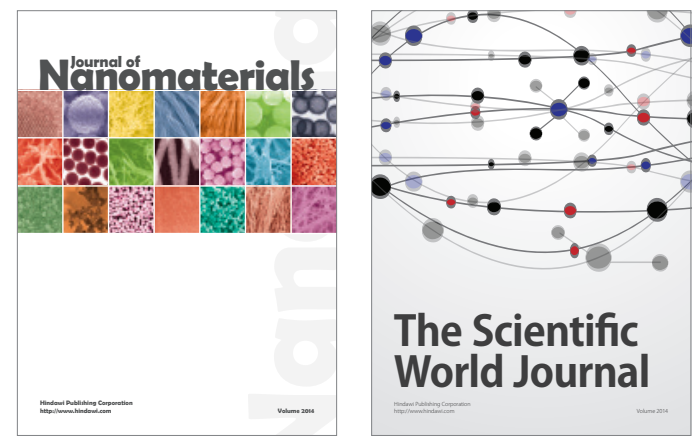

The Scientific World Journal
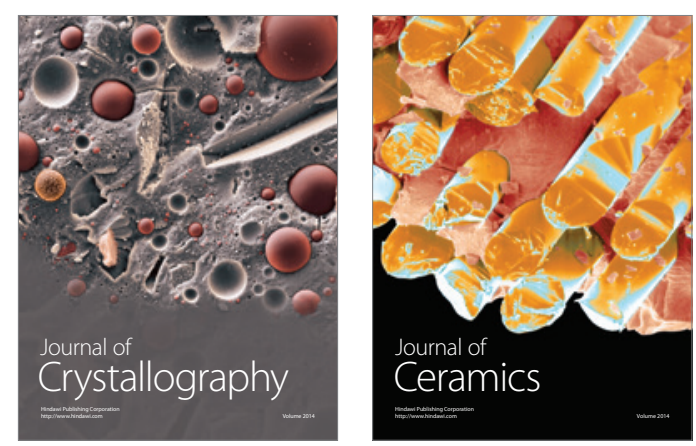
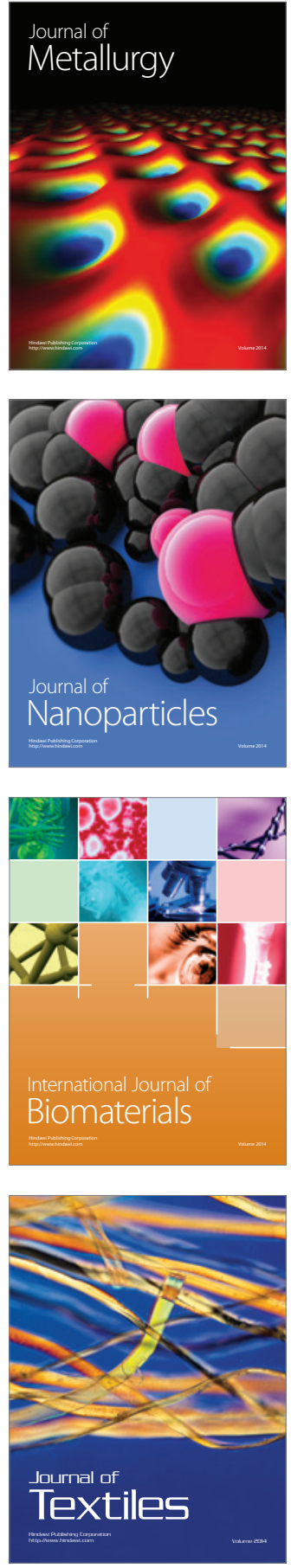